\title{
Transcription of the Sea Urchin U6 Gene In Vitro Requires a TATA-Like Box, a Proximal Sequence Element, and Sea Urchin USF, Which Binds an Essential E Box
}

\author{
JIAN-MING LI, REBECCA A. PARSONS, AND WILLIAM F. MARZLUFF* \\ Department of Biochemistry and Biophysics and Program in Molecular Biology and Biotechnology, \\ University of North Carolina at Chapel Hill, Chapel Hill, North Carolina 27599
}

Received 19 August 1993/Returned for modification 7 October 1993/Accepted 21 December 1993

\begin{abstract}
The tandemly repeated gene set encoding the sea urchin U6 gene has been cloned from the sea urchin Strongylocentrotus purpuratus. The U6 gene is transcribed by RNA polymerase III in a sea urchin nuclear extract. Like that of the vertebrate $U 6$ genes, transcription of the sea urchin U6 gene does not require any internal sequences or $3^{\prime}$ sequences but requires only $5^{\prime}$ flanking sequences. Only 88 nucleotides of $5^{\prime}$ flanking sequence are required for maximal expression in vitro. Mutagenesis experiments demonstrated the requirement for three elements, a CACGTG element at -80 , a proximal sequence element at about -55 , and the TATA-like box at -25 . The major protein in sea urchin extracts that interacts with the CACGTG element is sea urchin USF, and immunodepletion of sea urchin USF greatly reduces transcription. The USF binding site in the U6 gene is highly homologous (11 of 13 nucleotides) with the USF binding sites found in the promoter of the $S$. purpuratus spec genes.
\end{abstract}

The genes encoding the spliceosomal small nuclear RNAs (snRNAs) and some other snRNAs in metazoans have unusual promoter structures (27). Most of these genes are transcribed by RNA polymerase II, but some, including the U6 $(12,28)$ and 7SK RNAs (24), are transcribed by RNA polymerase III. Two major sequence elements are required for the expression of vertebrate snRNAs, a distal sequence element located at about -200 relative to the transcription start site and the proximal sequence element (PSE) located at about -55 . The PSE sequence has been conserved among different vertebrate snRNA genes (27). The PSE determines the start site of transcription. Some of the same factors, e.g., the Oct-1 factor $(5,25,34)$, and probably the factor(s) which binds to the PSE (19), are required for the transcription of snRNAs by both RNA polymerase II and RNA polymerase III. Surprisingly, in the vertebrate snRNA genes transcribed by RNA polymerase II there is no TATAA box, but in the snRNA genes transcribed by RNA polymerase III there is a TATAA box $(14,27)$, which presumably interacts with TFIIIB to direct the start of transcription.

Much less is known about invertebrate snRNA promoters. There are conserved sequences in both Caenorhabditis elegans (35) and Drosophila melanogaster (1) snRNA genes that are at the position expected for the PSE. A number of sea urchin snRNA promoters have been characterized, and while there are some similarities among the promoters, there are also striking differences. The sea urchin U1 (40), U2 (33), and U7 (32) genes all have an element at about -55 , the position of the PSE, which is required for transcription. There is no obvious sequence similarity among any of these elements (40). There are also distal sequences required for transcription of the U1 snRNA gene in vivo and distal elements which stimulate the expression of the U2 gene $(33,40)$. There is no

\footnotetext{
* Corresponding author. Mailing address: Program in Molecular Biology and Biotechnology, 132 MBBRL, CB \#7100, University of North Carolina at Chapel Hill, Chapel Hill, NC 27599. Phone: (919) 962-8920. Fax: (919) 966-6821. Electronic mail address: MARZLU@UNCVX1.oit.unc.edu.
}

similarity among these different distal elements. The sea urchin U2 snRNA genes, unique among metazoan snRNA genes transcribed by RNA polymerase II, have a required TATAA box (33).

Here we report the sequence requirements for expression of the sea urchin U6 snRNA gene. As with the vertebrate U6 snRNA genes, there is no internal promoter element, and there is a required TATA-like box. There are also two other elements absolutely required for transcription in vitro, a sequence at the expected position for a PSE between -45 and -65 and an E-box sequence at -80 . The E-box sequence binds to the sea urchin homolog of USF (suUSF), and immunodepletion experiments demonstrate that suUSF is required for U6 transcription by RNA polymerase III.

\section{MATERIALS AND METHODS}

Preparation of sea urchin nuclear extract. Sea urchins (Strongylocentrotus purpuratus or Lytechinus variegatus) were grown to the hatching blastula stage, and nuclei were prepared from embryos 1 to $2 \mathrm{~h}$ after hatching. Nuclei were prepared exactly as previously described (23). The nuclei were stored in liquid $\mathrm{N}_{2}$. Nuclear extract was prepared as previously described (23) except for the final dialysis step, which was done for $4 \mathrm{~h}$ against $80 \mathrm{mM} \mathrm{KCl}-25 \mathrm{mM}$ HEPES ( $N$-2-hydroxyethylpiperazine- $N^{\prime}$-2-ethanesulfonic acid) (pH 7.5)-0.1 mM EDTA-20\% glycerol-1 mM dithiothreitol (DTT) $-0.1 \mathrm{mM}$ phenylmethylsulfonyl fluoride. For some of the mobility shift experiments, nuclei were prepared from frozen embryos processed by the method of Calzone et al. (4). These nuclei were also purified by centrifugation through $2 \mathrm{M}$ sucrose as described previously (23) prior to preparation of the nuclear extract.

In vitro transcription. The conditions for transcription were optimized for each extract with respect to protein, DNA template, and $\mathrm{KCl}$ and $\mathrm{Mg}^{2+}$ concentrations. Typically, the DNA concentration was $80 \mu \mathrm{g} / \mathrm{ml}$, the protein concentration was 1 to $2 \mathrm{mg} / \mathrm{ml}, \mathrm{KCl}$ was $60 \mathrm{mM}$, and $\mathrm{MgCl}_{2}$ was $5 \mathrm{mM}$. Supercoiled templates were used routinely although identical results were obtained with linear templates. 
The 20- $\mu$ l transcription reaction mixture contained 20 mM HEPES (pH 7.5), 1 mM DTT, 1 mM EGTA [ethylene glycol-bis( $\beta$-aminoethyl ether)- $N, N, N^{\prime}, N^{\prime}$-tetraacetic acid], 1 $\mathrm{mM}$ spermidine, $500 \mu \mathrm{M}$ (each) unlabeled ribotriphosphate, and $25 \mu \mathrm{M}$ radiolabeled triphosphate (either $\left[\alpha-{ }^{32} \mathrm{P}\right] \mathrm{GTP}$ or $\left[\alpha-{ }^{32} \mathrm{P}\right] \mathrm{UTP}$ at $500 \mu \mathrm{Ci} / \mathrm{ml}$; final specific activity, $20 \mathrm{Ci} / \mathrm{mol}$ ).

All the components except the extract were mixed on ice, and the extract was added last. The $S$. purpuratus extracts were incubated at $15^{\circ} \mathrm{C}$ for $30 \mathrm{~min}$, and the L. variegatus extracts were incubated at $20^{\circ} \mathrm{C}$ for $30 \mathrm{~min}$. The reactions were terminated by addition of $100 \mu$ l of $0.3 \mathrm{M} \mathrm{NaCl}-1 \mathrm{mM}$ EDTA- $0.1 \%$ sodium dodecyl sulfate (SDS) $-100 \mu \mathrm{g}$ of yeast tRNA. A total of $60 \mu \mathrm{g}$ of proteinase $\mathrm{K}$ was added, and the reaction mixture was incubated for an additional $30 \mathrm{~min}$ at $37^{\circ} \mathrm{C}$. The samples were extracted with phenol-chloroform, and the RNA was recovered from the aqueous phase by precipitation with ethanol.

The RNA products were resolved on an $8 \%$ polyacrylamide-7 M urea gel. The gel was stained with ethidium bromide $(1 \mu \mathrm{g} / \mathrm{ml})$ for $5 \mathrm{~min}$ and then destained in water for 20 min. The gel was photographed under UV illumination with a red filter. The gel was then dried, and the products were detected by autoradiography or by using a PhosphorImager (Molecular Dynamics).

Construction of promoter mutations. The tandemly repeated $S$. purpuratus U6 gene (nucleotide sequence accession number X76389) was cloned from genomic DNA by PCR (29a). A U6 maxigene was constructed, one which has 21 nucleotides (nt) of pUC18 polylinker inserted at position 86 of the U6 sequence, and this maxigene was used in most of the experiments. Deletion mutations containing 1,727 to $266 \mathrm{nt}$ of 5 ' flanking sequence were constructed with convenient restriction enzyme sites. Further deletions were made by the exonuclease III-mung bean nuclease nested deletion procedure (9), starting with the gene containing $266 \mathrm{nt}$ of $5^{\prime}$ flanking sequence. Site-directed mutagenesis was performed by the method of Kunkel (15) with the gene with $856 \mathrm{nt}$ of $5^{\prime}$ flanking sequence. All mutations were confirmed by sequencing.

Mobility shift assay. Mobility shift assays were performed in $20 \mathrm{mM}$ HEPES (pH 7.5)-5 mM $\mathrm{MgCl}_{2}-60 \mathrm{mM} \mathrm{KCl}-1 \mathrm{mM}$ DTT $-0.1 \%$ Triton X-100-10\% glycerol, with $100 \mu \mathrm{g}$ of poly (dI-dC) per $\mathrm{ml}$ as a nonspecific competitor. Identical results were obtained when sonicated salmon sperm DNA was used as competitor. Different competitor oligonucleotides were added as indicated in the figure legends. A total of 10 to $20 \mu \mathrm{g}$ of nuclear protein was incubated on ice in buffer for 10 min prior to the addition of 1 to $2 \mathrm{ng}$ of radiolabeled probe. The reaction mixture was incubated for $30 \mathrm{~min}$ at $15^{\circ} \mathrm{C}$. The DNA-protein complex was resolved from free probe on a $4 \%$ polyacrylamide gel in $0.05 \mathrm{M}$ Tris-borate- $0.5 \mathrm{mM}$ EDTA. The gel was dried and visualized by autoradiography.

UV cross-linking of DNA-binding proteins. The 11-nt oligonucleotide CCGGGAACACG containing half of the E-box sequence was annealed to the complementary 18-nt complete E-box oligonucleotide CGCCGTAAGCACGTGTTC. 5-Bromo-dUTP $(100 \mu \mathrm{M})$ was added together with the Klenow fragment of DNA polymerase I, and the reaction mixture was incubated for $5 \mathrm{~min}$ at room temperature. dATP, dGTP, and dTTP were added to a final concentration of $300 \mu \mathrm{M}$ followed by $20 \mu \mathrm{Ci}$ of $\mathrm{dCTP}(8,000 \mathrm{Ci} / \mathrm{mmol})$, and incubation was continued for an additional $10 \mathrm{~min}$. The labeled probe was used in the mobility shift assay, and the gel was irradiated for $20 \mathrm{~min}$ at room temperature with an inverted UV box $(300 \mathrm{~nm}$, UV Products) at a distance of $4 \mathrm{~cm}$. The specific DNA-protein complex was cut out and eluted from the gel. The eluted complex was treated with $1 \mathrm{U}$ of DNase I for $15 \mathrm{~min}$ at $25^{\circ} \mathrm{C}$.
The sample was then analyzed by SDS-polyacrylamide gel electrophoresis. The gel was dried, and the labeled proteins were visualized by autoradiography.

Immunodepletion of suUSF. Immunodepletion was carried out essentially by the method of Luo et al. (22). A total of 10 to $20 \mu \mathrm{l}$ of protein A-Sepharose 4 Fast Flow (Pharmacia) beads was washed and packed into a column (1-ml pipette tip) and equilibrated in $25 \mathrm{mM}$ HEPES ( $\mathrm{pH} 7.6$ )-20\% glycerol-0.1 $\mathrm{mM}$ EDTA-100 mM KCl-0.025\% Nonidet P-40-0.125 mM EGTA-500 $\mu \mathrm{g}$ of bovine serum albumin-1 mM DTT $-0.1 \mathrm{mM}$ phenylmethylsulfonyl fluoride. Nuclear extract $(100 \mu \mathrm{l})$ was incubated with $10 \mu \mathrm{l}$ of affinity-purified suUSF antibody for 1 $h$ on ice. The mixture was then passed through a protein A-Sepharose column. For the mock depletions, the extract was incubated in the same buffer without the antibody and then passed over the protein A-Sepharose column.

Materials. Sea urchins were collected from the Gulf of Mexico (L. variegatus) or obtained from Marinus (Venice, Calif.) ( $S$. purpuratus). Oligodeoxynucleotides were synthesized in the Oligonucleotide Core Facility in the Lineberger Comprehensive Cancer Center at the University of North Carolina at Chapel Hill. $\alpha$-Amanitin and 5-bromo-2-dUTP were from Sigma Chemical Co. (St. Louis, Mo.). Rabbit antiserum against suUSF was a generous gift of Bill Klein.

\section{RESULTS}

The sea urchin snRNA genes expressed in oogenesis and early embryogenesis are present in tandemly repeated units. We recently cloned the 2-kb tandem repeat of the U6 genes from the sea urchin $S$. purpuratus (29a). Each tandemly repeated unit contains a single functional U6 gene, whose sequence is the same as that of the major U6 snRNA expressed in S. purpuratus eggs and embryos. A 127-nt maxigene with 21 nt of polylinker sequence inserted at nt 86 of the U6 RNA sequence was used in most of these experiments. We refer to this gene as $\mathrm{U} 6_{M}$. The structure of the $\mathrm{U6}_{\mathrm{M}}$ gene is shown in Fig. 1, with the restriction sites used in the deletion analysis indicated as well as the sequence of the insert to make the U6 maxigene. The structure of the $\mathrm{U}_{\text {globin }}$ gene, which has the U6 coding region replaced with a portion of the human $\beta$-globin coding region, is also shown in Fig. 1.

The $\mathrm{U6}_{\mathrm{M}}$ gene was transcribed by RNA polymerase III when it was incubated with a sea urchin nuclear extract prepared from $S$. purpuratus or $L$. variegatus blastula embryos at a rate comparable to that for the intact U6 gene (data not shown). We have used the $U 6_{M}$ maxigene in the rest of the experiments in this paper, since it is transcribed as well as the intact U6 gene and we have observed labeling of the endogenous U6 RNA with $\left[\alpha-{ }^{32}\right.$ P]UTP in some extracts (see Fig. 2C).

Sequences required for $\mathrm{U} 6$ transcription in vitro. A series of $5^{\prime}$ deletion mutants containing $1.8 \mathrm{~kb}$ to $50 \mathrm{nt}$ of $5^{\prime}$ flanking sequence were constructed. Transcription of the U6 gene was similar from all templates containing $88 \mathrm{nt}$ or more of $5^{\prime}$ flanking sequence (Fig. 2A, lanes 2 to 6; Fig. 2B, lanes 2 to 5). The apparent reduction in expression in lanes 3 and 4 (Fig. 2A) was due to reduced recovery in these samples, as judged by staining of the gel. Removal of the next $18 \mathrm{nt}$, leaving only 70 nt of $5^{\prime}$ flanking sequence, abolished transcription (Fig. 2A, lane 7; Fig. 2B, lane 6). Thus, there is a required sequence present between 70 and $88 \mathrm{nt} 5^{\prime}$ of the U6 gene, but no additional distal sequences are required for transcription in vitro.

To determine whether any elements in the coding region were required for transcription, the U6 coding region was replaced with a fragment of the $\beta$-globin sequence in reverse 

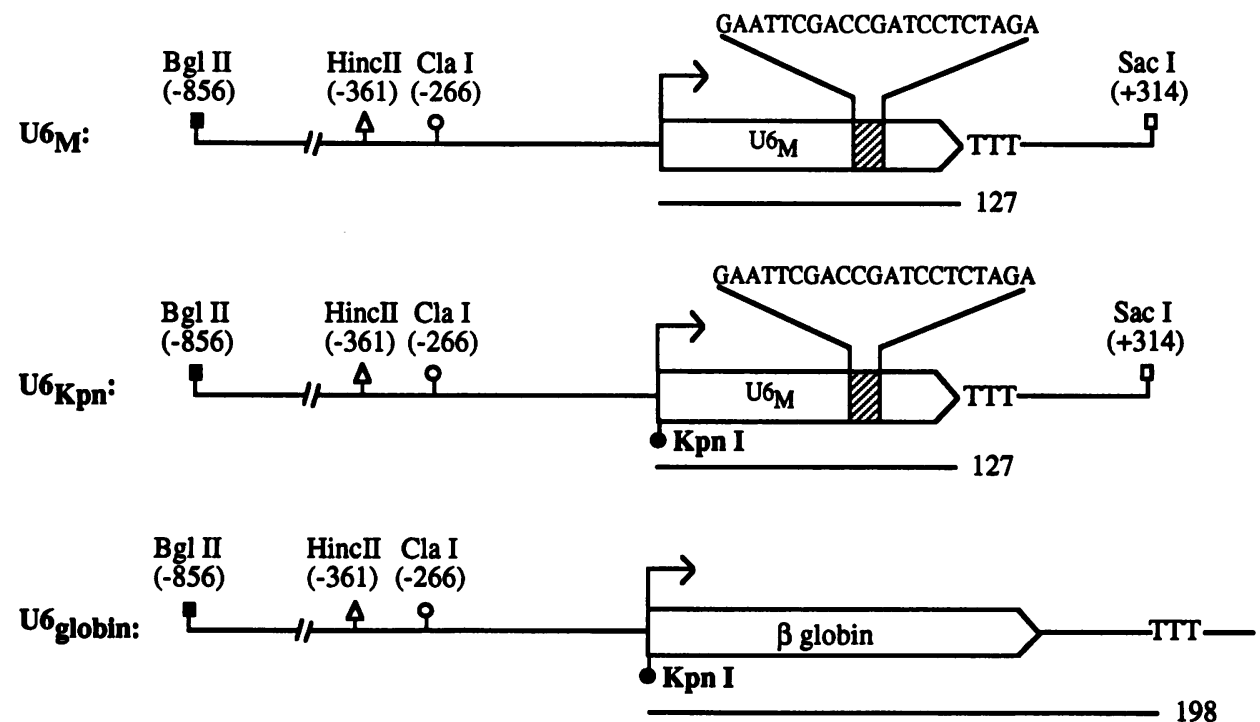

FIG. 1. Structure of the U6 gene. The structure of the U6 maxigene with a 21-nt insertion at nt $86\left(\mathrm{U} 6_{M}\right)$ used in most of these experiments is shown. The restriction enzyme sites used in construction of the initial 5' deletion mutants are also shown. In most of the experiments reported here, we used the U6 $6_{M}$ gene extending from the BglII site to the SacI site. Below the U6 ${ }_{M}$ gene is shown the U6 $6_{\mathrm{Kpn}}$ gene. This gene has a KpnI site spanning the initiation of transcription, and this site was introduced into the U6 $6_{M}$ gene by site-directed mutagenesis. Also shown is the U6 $6_{\text {globin }}$ gene with the U6 coding region replaced by the human $\beta$-globin coding region. Under each gene construct, the expected size of the transcript in nucleotides is indicated.

orientation followed by an RNA polymerase III termination site (20) (a gift of S. Lobo and N. Hernandez). The U6 $6_{\text {globin }}$ gene has a KpnI site overlapping the transcription start site. We introduced a KpnI site into the sea urchin $\mathrm{U6}_{\mathrm{M}}$ gene to allow the insertion of the globin sequence and as a control for changing the sequences around the start site. The $\mathrm{U} 6_{\mathrm{Kpn}}$ gene was transcribed at a lower rate than the $U 6_{M}$ gene (Fig. $2 \mathrm{C}$, lanes 3 and 4). In this experiment, UTP was used as a label and the endogenous U6 RNA was labeled in the terminal addition reaction described previously by Lund and Dahlberg (21).

Transcription of the normal U6 gene in this extract yielded a product which comigrated with authentic U6 RNA (Fig. 2C, lane 2). Replacing the coding region in this gene with the globin sequence did not further reduce transcription, demonstrating that there were no essential elements internal or $3^{\prime}$ of the U6 gene (Fig. 2C, lane 5).

Regions in the first $80 \mathrm{nt}$ required for transcription of the U6 gene. To identify the elements required for transcription in the $88 \mathrm{nt} 5^{\prime}$ to the U6 gene, a series of scanning mutations covering 10-nt intervals of the U6 promoter from the construct containing $856 \mathrm{nt}$ of $5^{\prime}$ flanking sequence were created. Alteration of the sequences between -50 and -90 in 10-nt blocks resulted in abolition of U6 transcription (Fig. 3A, lanes 3 to 6$)$. However, changing the sequences between -33 and -50 reduced transcription by only about a factor of 50 to $70 \%$ (Fig. 3A, lanes 7 and 8). Alteration of the sequences between the TTAAA and the start site also allowed continued transcription of the U6 gene (Fig. 3A, lane 10; Fig. 3B, lane 6), while converting the TTAAA to a GC-rich sequence reduced transcription 80 to $90 \%$ (Fig. 3A, lane 9; Fig. 3B, lane 3). Changing the TTAAA sequence to a canonical TATAA sequence did not increase transcription but actually reduced transcription $40 \%$ (Fig. 3B, lane 4). The TTAAA sequence is important but not essential for transcription, while the essential elements are located between -50 and $-88 \mathrm{nt} 5^{\prime}$ of the gene.
Two required sequence elements are located between $\mathbf{- 5 0}$ and $\mathbf{- 8 8}$. The relatively large region required for transcription defined by the 10 -nt scanning mutations suggested that there might be more than one element in this region. Since sequences distal to -70 are absolutely required for transcription (Fig. 2B), the 5' deletion analysis localizes an essential element between -71 and -88 . To see whether any additional elements were present, we created five additional scanning mutations, each of $5 \mathrm{nt}$ (5-1 to 5-5), which span the region from -50 to -76 , to more precisely define the sequence requirements for transcription located in this region. Figure 4A shows that mutant 5-1 (from -72 to -76 ) was expressed at $25 \%$ of the control, but was still expressed (Fig. 4A, lane 3), while mutant 5-2 (from -67 to -71 ) was reproducibly expressed at a higher rate (Fig. 4A, lane 4). Together with the deletion results, these two mutations define one essential region between $n t-76$ and -88 . Mutant 5-3 (nt -62 to -66 ) was not expressed, showing that these $5 \mathrm{nt}$ are critical for expression, while mutant 5-4 (nt -57 to -61) was expressed at less than $10 \%$ of the level for the intact $\mathrm{U6}_{M}$ gene (Fig. 4A, lane 6). Mutant 5-5 (nt -52 to -56 ) was expressed at $15 \%$ of the control level (Fig. 4A, lane 7).

These results are entirely consistent with the results with the larger scanning mutations in Fig. $3 \mathrm{~A}$ and define two regions absolutely required for expression: one, defined by the deletion mutations, extends from -88 to -76 , and the other, defined by the scanning mutations, extends from -66 to about -50 , with the $5^{\prime}$ end of this region essential for expression. These may represent binding sites for two different factors, or could be an extended binding site for a single factor, which recognizes disparate parts of the sequence. As we show below, there are two distinct factors which bind to this region: suUSF which binds between -70 and -88 and a factor which binds between -43 and -66 . We term this sequence element the PSE, on the basis of its location relative to the transcription start site, 

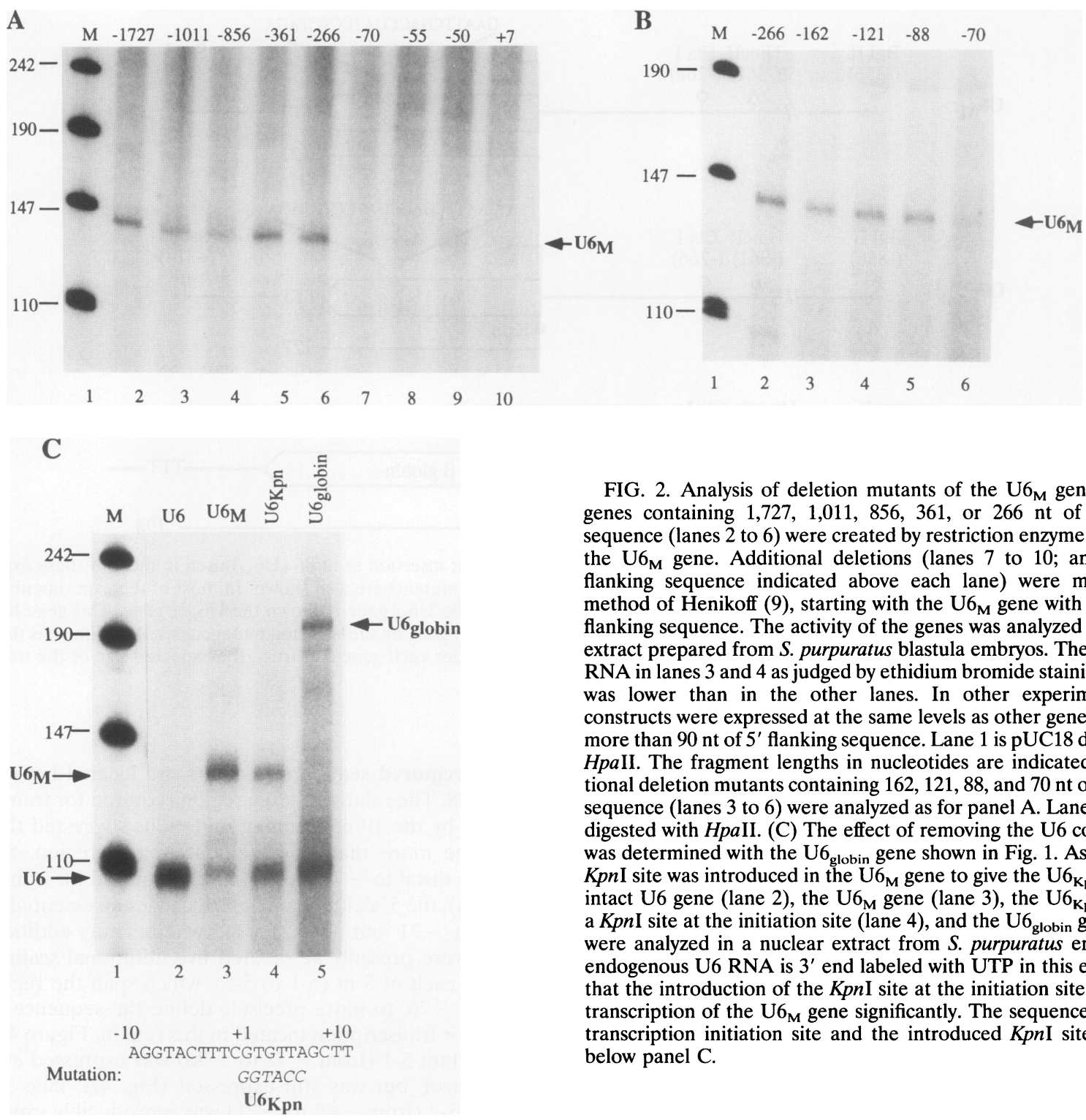

FIG. 2. Analysis of deletion mutants of the $U 6_{M}$ gene. (A) $U 6_{M}$ genes containing $1,727,1,011,856,361$, or $266 \mathrm{nt}$ of $5^{\prime}$ flanking sequence (lanes 2 to 6 ) were created by restriction enzyme digestion of the $\mathrm{U} 6_{\mathrm{M}}$ gene. Additional deletions (lanes 7 to 10 ; amount of $5^{\prime}$ flanking sequence indicated above each lane) were made by the method of Henikoff (9), starting with the U6 $6_{M}$ gene with $266 \mathrm{nt}$ of $5^{\prime}$ flanking sequence. The activity of the genes was analyzed in a nuclear extract prepared from $S$. purpuratus blastula embryos. The recovery of RNA in lanes 3 and 4 as judged by ethidium bromide staining of the gel was lower than in the other lanes. In other experiments, these constructs were expressed at the same levels as other genes containing more than $90 \mathrm{nt}$ of $5^{\prime}$ flanking sequence. Lane 1 is pUC18 digested with HpaII. The fragment lengths in nucleotides are indicated. (B) Additional deletion mutants containing $162,121,88$, and $70 \mathrm{nt}$ of $5^{\prime}$ flanking sequence (lanes 3 to 6 ) were analyzed as for panel A. Lane 1 is pUC18 digested with $\mathrm{HpaII}$. (C) The effect of removing the U6 coding region was determined with the $\mathrm{U} 6_{\text {globin }}$ gene shown in Fig. 1 . As a control, a $K p n I$ site was introduced in the $\mathrm{U} 6_{M}$ gene to give the $\mathrm{U} 6_{K p n}$ gene. The intact U6 gene (lane 2), the $\mathrm{U} 6_{\mathrm{M}}$ gene (lane 3 ), the $\mathrm{U} 6_{\mathrm{Kpn}}$ gene with a KpnI site at the initiation site (lane 4), and the U6 $6_{\text {globin }}$ gene (lane 5) were analyzed in a nuclear extract from $S$. purpuratus embryos. The endogenous U6 RNA is 3' end labeled with UTP in this extract. Note that the introduction of the KpnI site at the initiation site reduces the transcription of the $\mathrm{U} 6_{\mathrm{M}}$ gene significantly. The sequence around the transcription initiation site and the introduced $K p n I$ site are shown below panel C.

although there is no obvious sequence similarity between this element and other sea urchin snRNA PSEs.

The $E$ box is required for $\mathrm{U} 6$ transcription. The results with the $80 \mathrm{~S}$ and $70 \mathrm{~S}$ scanning mutations, both of which abolished expression (Fig. 3A), suggested that there was a critical element which spanned the junction of these two scanning mutations. Inspection of the sequence between -71 and -90 revealed the presence of an E-box sequence (CACGTG) located between -77 and -82 (Fig. 3A). To test the possibility that the E-box sequence was required for U6 transcription, point mutations were made in the conserved nucleotides in the E box. Changing either the CA to TT or the TG to AA abolished activity of the U6 promoter in vitro (Fig. 4B, lanes 3 and 4). These mutations account for the effects seen with both the $80 \mathrm{~S}$ and $70 \mathrm{~S}$ scanning mutants. Either of these mutations abolishes binding of proteins which recognize E-box sequences. Thus, the sea urchin U6 promoter requires three major elements to function in vitro, an element containing an
E-box sequence centered at -80 , the PSE located at about -55 , and a TATA-like element at -25 .

suUSF binds to the U6 promoter. Mobility shift assays were used to detect factors which interact with the sea urchin U6 gene promoter. With the -38 to -88 -nt fragment labeled at the -88 end, a major complex (complex I) was identified in nuclear extracts from $L$. variegatus blastula embryos, which specifically bound to this fragment (Fig. 5A, lanes 2 and 3). Digestion of the end-labeled fragment with $C f o I$, which cuts at -68 and releases a labeled 20 -nt fragment, demonstrated that the sequences required for binding lay between -68 and -88 , the region containing the $\mathrm{E}$ box (Fig. $5 \mathrm{~A}$, lanes 5 and 6 ), while the sequence from -38 to -68 did not form this complex (data not shown). To confirm this result, a 20-nt probe containing the E-box sequence was synthesized and used in the mobility shift assay. There was specific binding of a factor to this probe, which was inhibited efficiently by the homologous probe (Fig. 5B, lanes 3 to 6). Binding was not inhibited by 
A

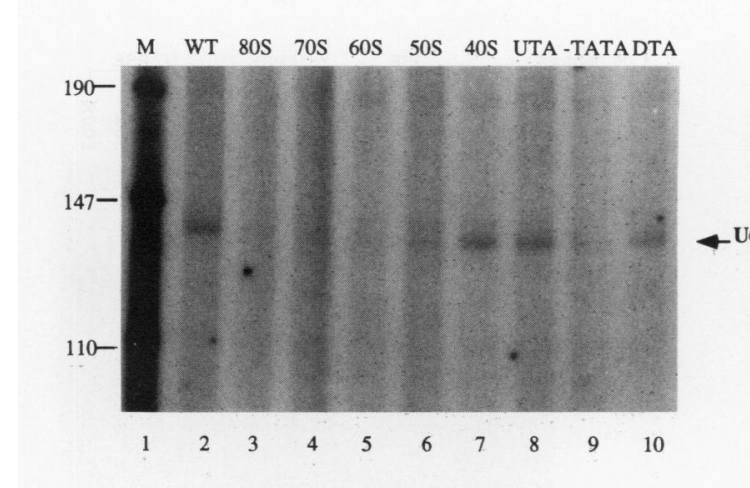

B

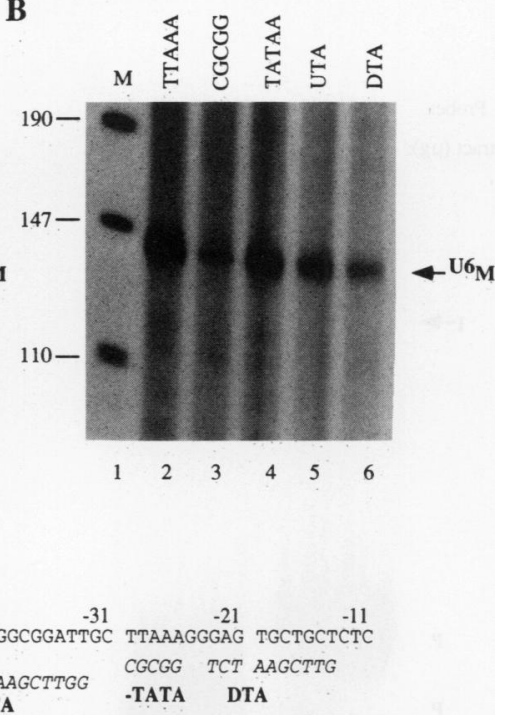

FIG. 3. Scanning mutations of the U6 promoter. (A) A series of 10-nt mutations were created in the U6 $6_{M}$ promoter from nt -90 to -14 . In addition, a 5-nt mutation was made in the TTAAA sequence. Each of these mutants was assayed in a nuclear extract prepared from $S$. purpuratus blastula embryos as described in Materials and Methods (lanes 2 to 10), and the gene analyzed is indicated above each lane. The sequence of the first $90 \mathrm{nt}$ of the U6 promoter and the sequence of the mutants are given below the figure. Lane 1 is pUC18 digested with $\mathrm{HpaII}$. (B) The effect of mutations in the vicinity of the TATA-like box was analyzed. The wild-type U6 $6_{M}$ promoter (lane 2) and mutants with the TTAAA sequence changed to a GC-rich sequence (lane 3) or to the canonical TATAA sequence (lane 4) as well as the UTA and DTA 10-nt mutations flanking the TTAAA sequence (lanes 5 and 6, respectively) were analyzed as for panel A. Lane 1 is pUC18 digested with HpaII.

oligonucleotides containing the sea urchin U1 or U2 PSE sequences (Fig. 5B, lanes 7 to 14).

CACGTG is the core sequence of the human USF binding site (30) and also the consensus sequence for a group of basic helix-loop-helix DNA-binding proteins which bind to the $\mathrm{E}$ box, CANNTG (16), which include MyoD (7) and Myc (1a).
The sequence flanking the CACGTG is very similar (11 of 13 nt [Fig. 4B]) to the sequence in the promoter of the spec genes $(11,36)$, a class of genes which is expressed in the aboral ectoderm of sea urchins later in development and which has been shown to bind to suUSF $(11,36)$.

To identify the factors interacting with the U6 E-box se-
A

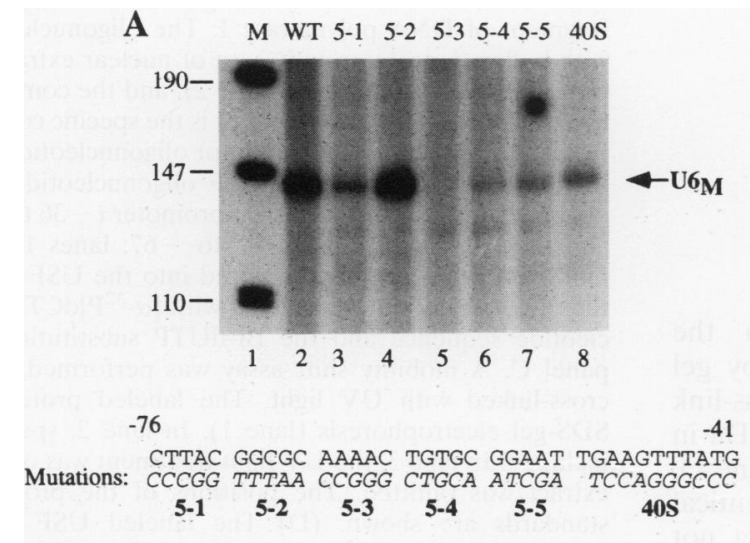

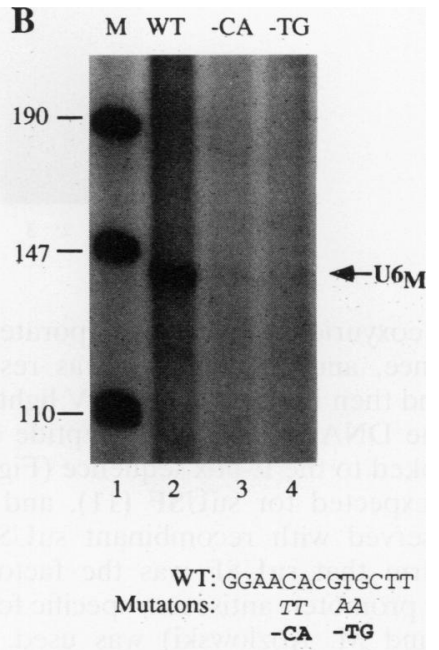

Spec USF site: GGT-CACGTGCTT Human USF site: GGC-CACGTGACC

FIG. 4. Two essential regions of the U6 promoter. (A) A series of 5-nt mutations between nt 52 and 76 were made. The sequence of these mutations is shown below panel $A$, and they are designated 5-1 through 5-5. These mutant $U 6_{M}$ genes were analyzed together with the wild type and 40S 10-nt mutation (lanes 2 to 8). The genes were incubated in a nuclear extract prepared from $S$. purpuratus blastula embryos. Lane 1 is pUC18 digested with HpaII. (B) Two-base-pair mutations were made in the conserved nucleotides in the E-box sequence. The wild-type U6 $6_{M}$ gene (lane 2) and the mutant genes (lanes 3 and 4) were analyzed as described for panel A. Lane 1 is pUC18 digested with HpaII. The sequence of the $\mathrm{E}$ box and the mutations are shown below the figure. The sea urchin spec gene USF sequence and the human USF sequence are also shown. 


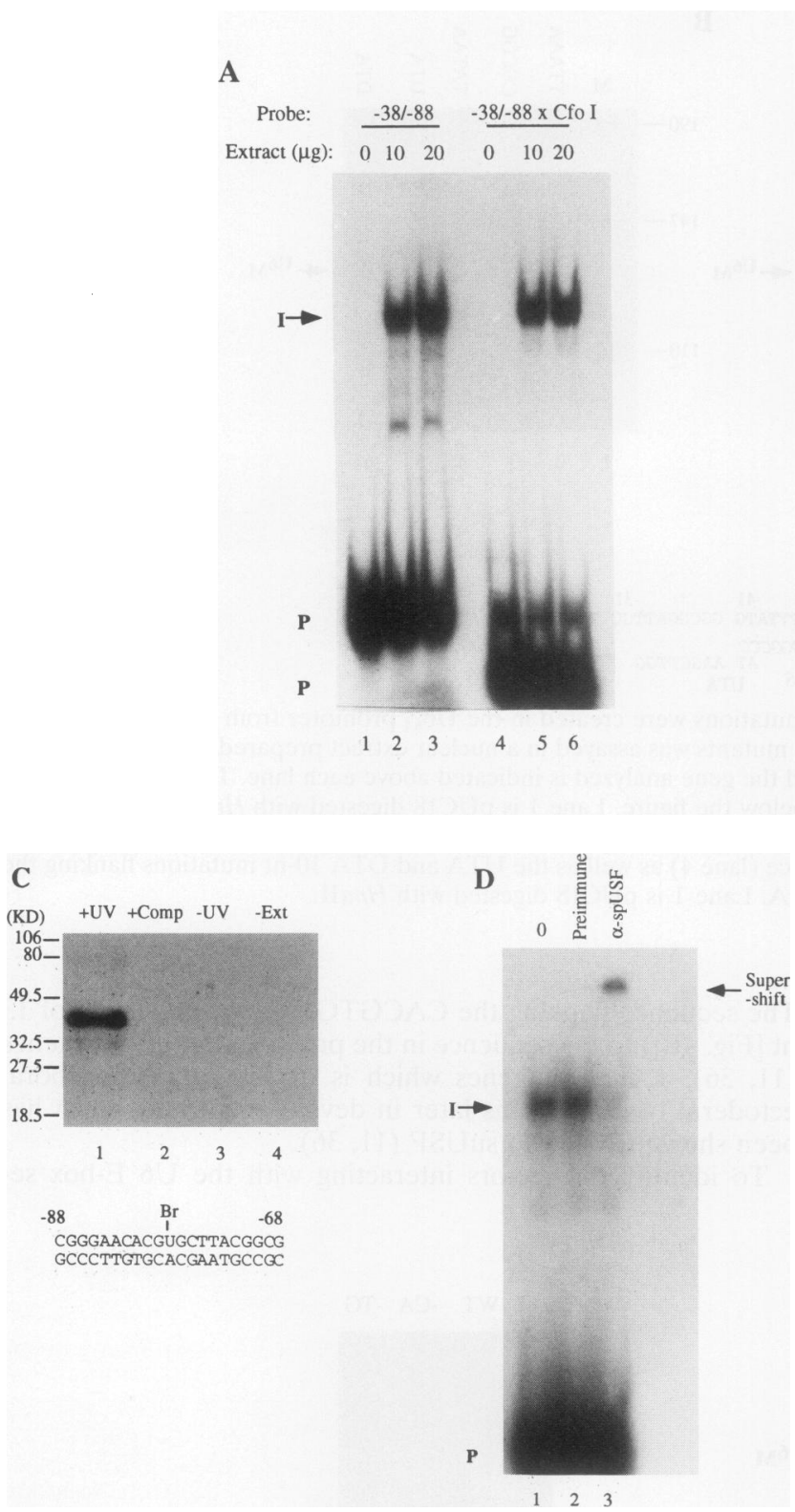

quence, bromodeoxyuridine was incorporated into the CACGTG sequence, and the complex was resolved by gel electrophoresis and then irradiated with UV light to cross-link the proteins to the DNA. A major polypeptide of $38 \mathrm{kDa}$ in mass was cross-linked to the E-box sequence (Fig. 5C, lane 1). This is the size expected for suUSF (11), and an identical complex was observed with recombinant suUSF (data not shown). To confirm that suUSF was the factor which was binding to the U6 promoter, antiserum specific for USF (a gift from W. Klein and M. Kozlowski) was used. Addition of antisera to suUSF to the DNA-binding reaction mixture resulted in a supershift, the formation of a larger complex (Fig. $5 \mathrm{D}$, lane 3), indicating that sea urchin USF was responsible for formation of complex I in the gel mobility shift assay (Fig. 5D, lane 1). No effect was observed with preimmune sera (Fig. 5D, lane 2). These results suggest that a factor which recognizes the E-box sequence, possibly suUSF, is required for transcription of the U6 snRNA gene by RNA polymerase III.

\section{$\mathbf{B}$}

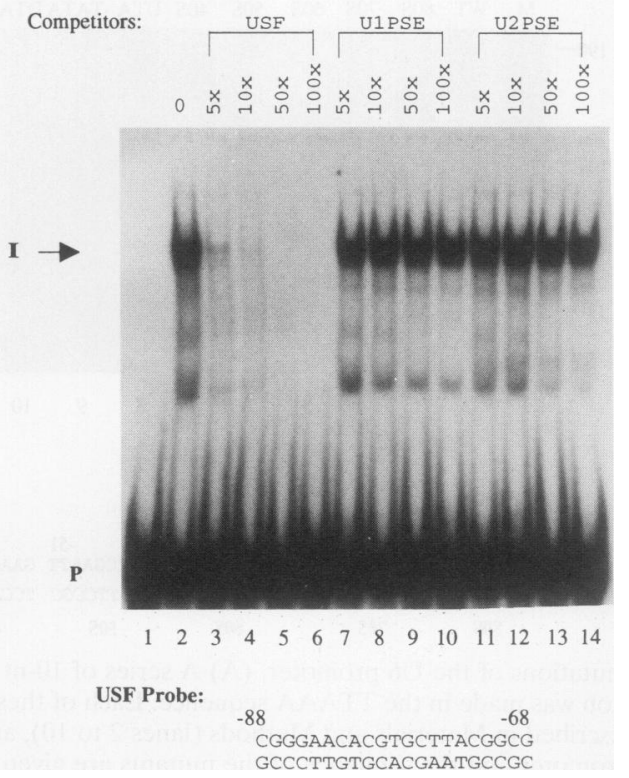

FIG. 5. suUSF binds to the E box in the U6 promoter. (A) An oligonucleotide extending from -38 to -88 was synthesized and labeled on the distal $(-88)$ end with $\left[\alpha-{ }^{32} \mathrm{P}\right] \mathrm{dCTP}$. The labeled fragment was incubated either in buffer (lane 1) or with $10 \mu \mathrm{g}$ (lane 2) or $20 \mu \mathrm{g}$ (lane 3) of nuclear protein prepared from $L$. variegatus blastula embryos, and the complexes were resolved by gel electrophoresis. The labeled fragment was digested with $C f o \mathrm{I}$ (which cut at $-68)$, and the labeled fragment ( -68 to -88$)$ was incubated in buffer (lane 4 ) or with 10 or $20 \mu \mathrm{g}$ of nuclear protein prepared from $L$. variegatus blastula embryos (lanes 5 and 6). There was a small amount of the probe which was not completely digested with CfoI (lane 4) which also was shifted in lanes 5 and 6 . The fragment from -38 to -68 was not labeled after the CfoI digestion. (B) A synthetic oligonucleotide containing $\mathrm{nt}-68$ to -88 (shown below panel B) was synthesized and labeled by filling in the overhangs with the Klenow fragment of DNA polymerase I. The oligonucleotide was incubated with buffer (lane 1) or with $5 \mu \mathrm{g}$ of nuclear extract prepared from $L$. variegatus blastula embryos (lane 2), and the complexes were resolved by gel electrophoresis. Complex I is the specific complex binding to the E-box oligonucleotide. Competitor oligonucleotides were added in the indicated molar excess: the USF oligonucleotide (lanes 3 to 6) and oligonucleotides from the LvU1 promoter ( -36 to -61 ; lanes 7 to 10) and the LvU2 promoter ( -45 to -67 ; lanes 11 to 14$)$. (C) 5-Bromodeoxyuridine was incorporated into the USF oligonucleotide, and the oligonucleotide was labeled with $\left[\alpha{ }^{32} \mathrm{P}\right] \mathrm{dCTP}$. The USF oligonucleotide sequence and the Br-dUTP substitution are shown below panel C. A mobility shift assay was performed, and complex I was cross-linked with UV light. The labeled protein was analyzed by SDS-gel electrophoresis (lane 1). In lane 2, specific competitor was included. In lane 3, the UV light treatment was omitted. In lane 4, the extract was omitted. The positions of the protein molecular mass standards are shown. (D) The labeled USF oligonucleotide was incubated with buffer (lane 1) or with $5 \mu \mathrm{g}$ of nuclear protein extract prepared from $L$. variegatus blastula embryos together with preimmune serum (lane 2) or antisera prepared against recombinant USF (lane 3).

suUSF is required for $\mathrm{U} 6$ transcription. To definitively identify suUSF as the factor involved in U6 transcription, suUSF was depleted from the extract with anti-USF antisera prepared against the recombinant protein (11). When the extract was incubated with antibody against suUSF and then 

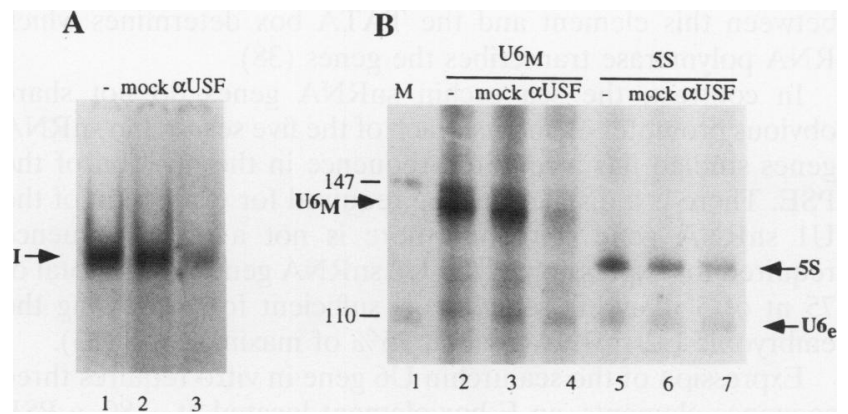

FIG. 6. USF is required for U6 transcription. (A) A nuclear extract was incubated with anti-USF antibody and passed over a protein A-Sepharose column ( $\alpha$ USF) or incubated with buffer and then passed over a protein A-Sepharose column (mock). The starting extract (-, lane 1), the mock-depleted extract (mock, lane 2), and the USFdepleted extract ( $\alpha \mathrm{USF}$, lane 3 ) were assayed for USF binding activity by the mobility shift assay. The USF complex (I) is indicated. (B) The same extracts were assayed for transcription of the $U 6_{M}$ gene (lanes 2 to 4 ) or the 5S RNA gene (lanes 5 to 7 ) with $\left[\alpha^{-32}\right.$ P]UTP as a label. Labeled transcripts: $\mathrm{U6}_{\mathrm{M}}$, transcript of the U6 maxigene; $5 \mathrm{~S}$, transcript of the 5S RNA gene; $\mathrm{U6}_{\mathrm{e}}$, end labeling of the endogenous U6 snRNA. Lane 1 is marker pUC18 digested with HpaII.

passed over a protein A-Sepharose column, more than $90 \%$ of the USF was removed as judged by the mobility shift assay (Fig. 6A, lanes 1 and 3). The transcription of the U6 gene was also reduced by $>90 \%$ in the extract depleted with anti-USF antisera (Fig. 6B, lane 4), while the mock-depleted extract contained USF (Fig. 6A, lane 2) and transcribed the U6 gene at $70 \%$ of the level of the untreated extract. The $5 \mathrm{~S}$ gene was transcribed in both the mock-depleted and the USF-depleted extracts (Fig. 6B, lanes 6 and 7), and there was only a modest reduction (two- to threefold in different experiments) in the amount of $5 \mathrm{~S}$ transcription while U6 transcription was reduced by more than 10 -fold, in parallel with the reduction in the amount of USF. The end labeling of the endogenous U6 snRNA was also not affected by depleting the extract of USF (Fig. 6B, lanes 4 and 7).

Detection of factors binding to the PSE. The mobility shift assay was used to identify additional factors which interact with the U6 promoter. When mobility shift experiments were done with a large probe, -38 to -88 , which spanned the entire region essential for transcription, the major complex observed at low protein concentrations was the USF complex, labeled complex I (Fig. 7A, lanes 2 and 3). When the protein concentration was increased, slowly migrating complexes, II and III, were formed, and at high protein concentrations, complex I was no longer present, suggesting that additional factors had bound with the probe (Fig. 7A, lanes 3 to 6). These additional complexes were due to a factor(s) interacting with other regions of the probe, since when the synthetic oligonucleotide probe containing only the USF site (nt -68 to -88 ) was incubated with the same extract, only complex I was observed and there were no slowly migrating complexes present (Fig. $7 \mathrm{~B}$, lanes 5 to 8 ). This result suggested that the additional factors responsible for complexes II and III were due to factors binding to other regions of the DNA probe. The loss of complex I with increasing protein concentration with the -38 to -88 probe suggested that some of the more slowly migrating complexes also contained suUSF (see below).

A synthetic oligonucleotide corresponding to the sequences from -43 to -68 was used in a mobility shift assay. This synthetic oligonucleotide formed two complexes, I' and II,
A

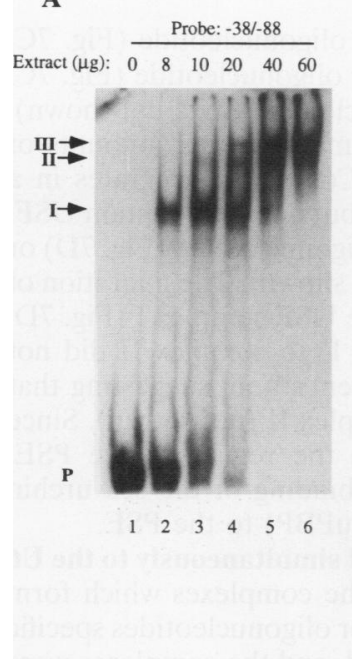

B
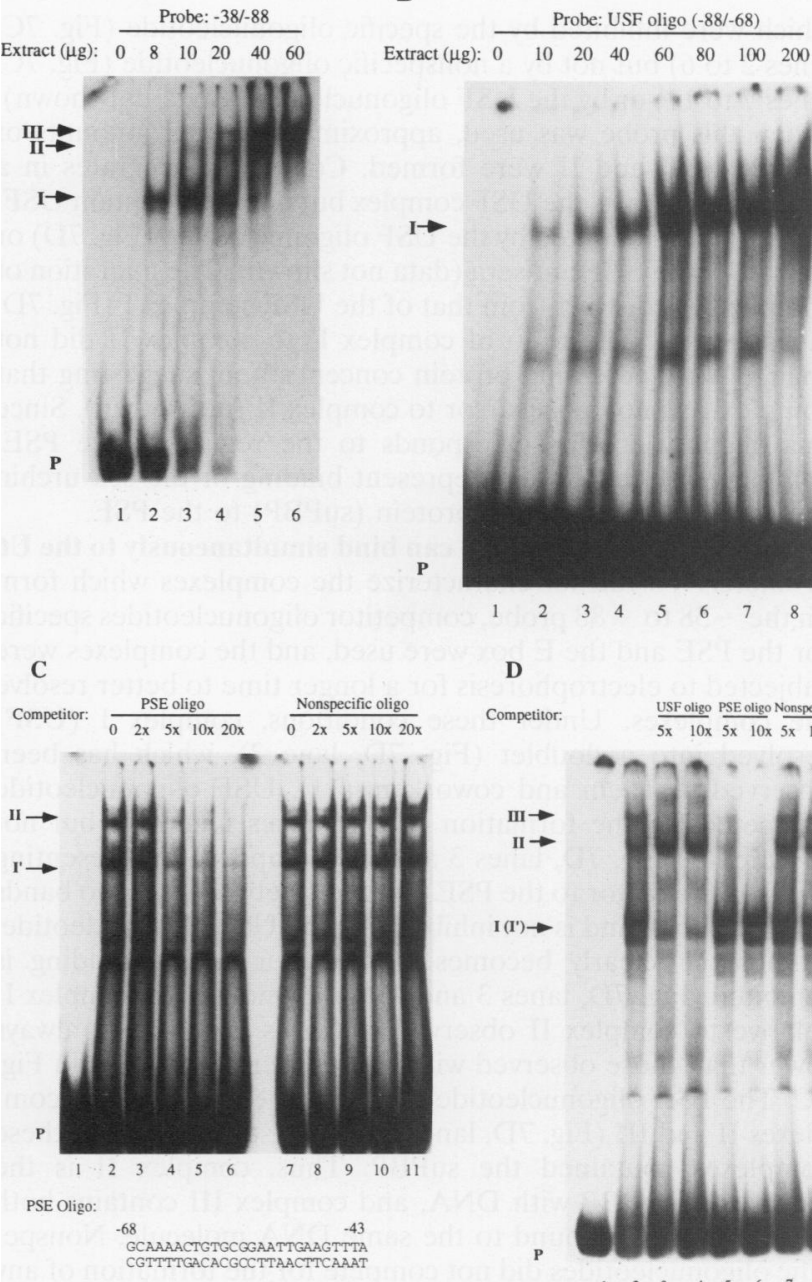

D

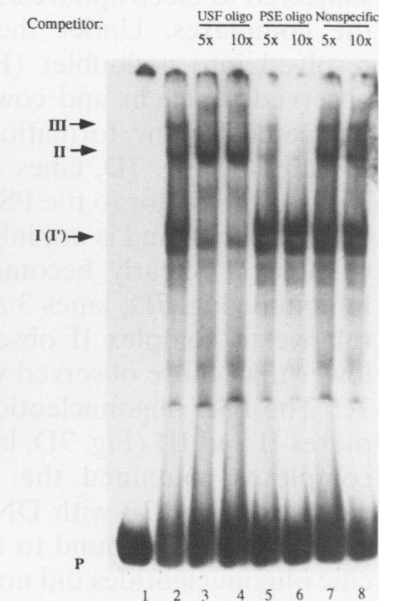

FIG. 7. A factor interacts with the U6 PSE sequence. (A) The -38 to -88 fragment used for Fig. $5 \mathrm{~A}$ was incubated in buffer (lane 1) or with increasing amounts of nuclear protein prepared from $L$. variegatus blastula embryos (lanes 2 to 6 ). At higher concentrations, additional complexes II and III were formed. Note that the amounts of protein used in lanes 4 to 6 are much higher than the amounts of protein used for Fig. 5A. (B) The synthetic oligonucleotide containing the $\mathrm{E}$ box ( -68 to -88 ) was labeled and incubated with buffer (lane 1) or with increasing amounts of nuclear protein from the same extract used for panel A. Only complex I was formed on this oligonucleotide at all protein concentrations. (C) A synthetic oligonucleotide from -43 to -68 was labeled with $\left[\alpha-{ }^{32} \mathrm{P}\right] \mathrm{dCTP}$ and incubated with buffer (lane 1) or with $10 \mu \mathrm{g}$ of nuclear protein prepared from $L$. variegatus blastula embryos (lanes 2 to 11). In lanes 3 to 6 , increasing concentrations of the same oligonucleotide were added, and in lanes 8 to 11, increasing concentrations of a nonspecific oligonucleotide were added. Two specific complexes ( $\mathrm{I}^{\prime}$ and II) were formed. Complex $\mathrm{I}^{\prime}$ migrates in a position similar to that of complex I but is not inhibited by the oligonucleotide which binds suUSF (Fig. 7D). (D) The oligonucleotide from -38 to -88 used for panel $A$ was incubated with buffer (lane 1) or with $20 \mu \mathrm{g}$ of nuclear protein prepared from $L$. variegatus blastula embryos (lanes 2 to 8 ), and the complexes were analyzed by electrophoresis. In lanes 3 and 4, a 5- and 10-fold excess of USF oligonucleotide was included; in lanes 5 and 6, a 5- and 10-fold excess of the PSE oligonucleotide ( -43 to -68 ) was included; and in lanes 7 and 8 , a 5and 10-fold excess of a nonspecific oligonucleotide was included Complex $I$ is the complex containing suUSF, complexes $I^{\prime}$ and II contain the suPBP, and complex III contains both suUSF and suPBP. Electrophoresis was for a longer time in this experiment to better resolve the complexes, and the suUSF complex (complex I) was resolved into a doublet. 
which were inhibited by the specific oligonucleotide (Fig. 7C, lanes 2 to 6 ) but not by a nonspecific oligonucleotide (Fig. 7C, lanes 7 to 11) or by the USF oligonucleotide (data not shown). When this probe was used, approximately equal amounts of complexes $\mathrm{I}^{\prime}$ and II were formed. Complex $\mathbf{I}^{\prime}$ migrates in a similar position as the USF complex but does not contain USF, since it is not inhibited by the USF oligonucleotide (Fig. 7D) or shifted by the USF antisera (data not shown). The migration of complex $I^{\prime}$ is distinct from that of the USF complex I (Fig. 7D, lanes 2 to 4$)$. The ratio of complex I' to complex II did not change with increasing protein concentration, suggesting that complex $\mathrm{I}^{\prime}$ is not a precursor to complex II (not shown). Since this oligonucleotide corresponds to the region of the PSE, complexes $I^{\prime}$ and II may represent binding of the sea urchin proximal element-binding protein (suPBP) to the PSE.

Both USF and the suPBP can bind simultaneously to the U6 promoter. To further characterize the complexes which form on the -38 to -88 probe, competitor oligonucleotides specific for the PSE and the E box were used, and the complexes were subjected to electrophoresis for a longer time to better resolve the complexes. Under these conditions, complex I (USF) resolved into a doublet (Fig. 7D, lane 2), which has been observed by Klein and coworkers (11). USF oligonucleotide competed for the formation of complexes I and III but not complex II (Fig. 7D, lanes 3 and 4). Complex I', representing binding of a factor to the PSE, migrates between the two bands in this doublet and is not inhibited by the USF oligonucleotide. Complex $I^{\prime}$ clearly becomes visible after usUSF binding is inhibited (Fig. 7D, lanes 3 and 4). The amounts of complex $I^{\prime}$ relative to complex II observed with this probe were always lower than those observed with the shorter probe used in Fig. 7C. The PSE oligonucleotide inhibited the formation of complexes II and III (Fig. 7D, lanes 5 and 6), suggesting that these complexes contained the suPBP. Thus, complex II is the complex of suPBP with DNA, and complex III contains both suPBP and USF bound to the same DNA molecule. Nonspecific oligonucleotides did not compete for the formation of any of the complexes (Fig. 7D, lanes 7 and 8).

\section{DISCUSSION}

The vertebrate snRNA promoters have been relatively well studied. Although some of these genes are transcribed by RNA polymerase II and some are transcribed by RNA polymerase III, they share factors for their expression. The sequence elements involved in U6 and $\mathrm{U} 2$ transcription are similar for the human snRNA genes $(13,19)$. The Oct-1 protein is required for expression of both U1 and U2 snRNA genes as well as for the transcription of the U6 and 7SK genes (26), and Sp1 may be involved in transcription of both the U6 and U2 snRNA genes in Xenopus laevis (17). The transcription of all the nucleoplasmic snRNAs also requires a conserved sequence element, the PSE, which interacts with PBP, the proximal element-binding protein $(31,39)$. All of the nucleoplasmic snRNA genes are thought to interact with the same PBP, although the functional equivalence of two PSEs has been demonstrated only for the U2 and U6 genes (19).

The U6 promoter has been studied in Saccharomyces cerevisiae and plants in addition to vertebrates. In $S$. cerevisiae, the U6 promoter has a major element located $3^{\prime}$ of the coding region which functions as a $\mathrm{B}$ box $(2,8)$. There are no known promoter elements shared among the yeast snRNA genes transcribed by RNA polymerase II, but little is known about other yeast snRNA promoter elements. In plants, the snRNA genes transcribed by RNA polymerase II share a PSE with the genes transcribed by RNA polymerase III (37), and the spacing between this element and the TATA box determines which RNA polymerase transcribes the genes (38).

In contrast, the sea urchin snRNA genes do not share obvious promoter elements. Each of the five sea urchin snRNA genes studied has a required sequence in the position of the PSE. There is a distal sequence required for expression of the U1 snRNA gene (40), but there is not a distal sequence required for expression of the U2 snRNA gene (33). A total of $75 \mathrm{nt}$ of $5^{\prime}$ flanking sequence is sufficient for expressing the embryonic U2 snRNA gene at $25 \%$ of maximal rate (33).

Expression of the sea urchin U6 gene in vitro requires three sequence elements, an E-box element located at -80, a PSE located at about -55 , and a TATA-like element located at about -25 . The major factor which interacts with the $\mathrm{E}$ box is the sea urchin homolog of USF. USF was first identified as a factor required for the expression of the adenovirus major late promoter (30). The duck homolog of USF is required for expression of the histone $\mathrm{H} 5$ gene in vitro (3). More recently, human USF has also been shown to act through the initiator elements in the adenovirus and human immunodeficiency virus promoters (6). USF binds to initiator sequences independently of its ability to bind to the E-box sequences (6). All of the known actions of USF (and indeed of proteins which bind to E-box sequences) are on genes transcribed by RNA polymerase II. In all of these cases, the USF binding site is located within $100 \mathrm{nt}$ of the transcription start site, either $5^{\prime}$ of the start site (adenovirus) or, in the case of the duck histone H5 gene, $3^{\prime}$ of the start site.

The E-box consensus, CANNTG, is found in many genes because of the simplicity of the consensus sequence. There is an E-box sequence in a similar location in the sea urchin U1 promoters, but this sequence does not bind USF well (18) and is not required for $U 1$ expression in vivo (40) or in vitro (18). There is also an E-box sequence at -77 to -82 of the human U6 promoter, but the sequence adjacent to the $\mathrm{E}$ box is not similar to the human USF consensus. It is not known whether this E-box sequence is involved in human U6 expression.

The sea urchin homolog of USF (suUSF) has been cloned by Kozlowski and coworkers (11). It is clearly identified as a USF homolog by the high conservation of the DNA binding domain with human USF (11). The suUSF protein has several regions of very high homology with the vertebrate USF proteins, particularly in the basic helix-loop-helix domain important for DNA binding and in a region around amino acid 150 which has been implicated in transcriptional activation (10). suUSF lacks the leucine zipper region located $\mathrm{C}$ terminally to the helixloop-helix domain, and instead, the suUSF ends immediately after the DNA binding domain, resulting in a polypeptide of 38 rather than $43 \mathrm{kDa}$. Since other basic helix-loop-helix proteins also lack the leucine zipper domain, it is unlikely that simply the loss of that domain accounts for the involvement of suUSF in transcription by polymerase III. It seems more likely that the activation domain of USF can function to activate transcription by both RNA polymerase II and RNA polymerase III.

There is a binding site for suUSF in the $5^{\prime}$ flanking region of the spec genes, a family of genes expressed in the aboral ectoderm of the larval sea urchin (11). Although this site is conserved in the spec genes among different sea urchin species, mutations in this site do not have any effect on the expression of the spec genes (11). Thus, as yet there is no direct evidence that suUSF acts to stimulate transcription of any genes by RNA polymerase II, although it certainly seems likely that there are some genes transcribed by RNA polymerase II that USF stimulates. The transcription by RNA polymerase III is possibly a result of the recruitment of TFIIIB rather than 
TFIID to the U6 TATA sequence. The PSE is probably critical in this interaction (29).

The second element necessary for expression is the PSE. This element is clearly distinct from the E box, although the PSE is nearly contiguous to the USF binding site. The PSE interacts with a protein factor (termed suPBP) as judged by the mobility shift assay. However, despite the fact that suUSF and the suPBP bind to adjacent sites, there is no evidence of cooperative binding (18). The formation of PSE-suPBP complexes takes place equally well on DNA fragments which contain and on those which lack the suUSF binding site. Complexes which contain both PBP and suUSF are readily detected (Fig. 7). Thus, there is no evidence for interaction between these two factors which affects their ability to bind DNA, although presumably interaction between these factors is involved in activation of transcription.

Finally, like the vertebrate U6 genes, the sea urchin U6 gene contains a TATA-like box which is necessary for high rates of transcription but is not essential for transcription. The sequence of the TATA-like box is probably not critical since the natural U6 sequence, TTAAA, is unusual, and the canonical TATAA box functions well in supporting U6 transcription (Fig. 3B).

There are no E-box elements present in the sea urchin U1, $\mathrm{U} 2$, or U7 snRNA genes which are involved in expression of these genes. Thus, suUSF is involved in transcription of the U6 snRNA gene but not of the other snRNA genes. Inspection of the sequences of the sea urchin U1, U2, U6, and U7 PSEs does not reveal any obvious sequence similarities, although each of these genes contains an essential element located at about -55 from the start site of transcription. It is possible that different sets of factors are involved in expression of each of the sea urchin tandemly repeated snRNA genes.

\section{ACKNOWLEDGMENTS}

This work was supported by grant GM27789 from NIH.

We thank William Klein and Mark Kozlowski (University of Texas, M. D. Anderson Cancer Center) for the generous gift of USF antisera and for helpful discussions. We thank Yang Luo and Robert Roeder (Rockefeller University) for advice on the immunodepletion experiments and Susan Lobo and Nouria Hernandez (Cold Spring Harbor Laboratory) for a gift of the human U6- $\beta$-globin chimeric gene.

\section{REFERENCES}

1. Beck, E., J. L. Jorcano, and A. Alonso. 1984. Drosophila melanogaster U1 and U2 small nuclear RNA genes contain common flanking sequences. J. Mol. Biol. 173:539-542.

1a.Blackwell, T. K., L. Kretzner, E. M. Blackwood, R. N. Eisenman, and $H$. Weintraub. 1990. Sequence-specific DNA binding by the c-Myc protein. Science 250:1149-1151.

2. Brow, D. A., and C. Guthrie. 1990. Transcription of a yeast U6 snRNA gene requires a polymerase III promoter element in a novel position. Genes Dev. 4:1345-1356.

3. Bungert, J., I. Kober, F. Düring, and K. H. Seifart. 1992. Transcription factor eUSF is an essential component of isolated transcription complexes on the duck histone $\mathrm{H} 5$ gene and it mediates the interaction of TFIID with a TATA-deficient promoter. J. Mol. Biol. 223:885-898.

4. Calzone, F. J., C. Höög, D. B. Teplow, A. E. Cutting, R. W. Zeller, R. J. Britten, and E. H. Davidson. 1991. Gene regulatory factors of the sea urchin embryo. I. Purification by affinity chromatography and cloning of P3A2, a novel DNA-binding protein. Development 112:335-350.

5. Das, G., D. Henning, and R. Reddy. 1987. Structure, organization, and transcription of Drosophila U6 small nuclear RNA genes. J. Biol. Chem. 262:1187-1193.

6. Du, H., A. L. Roy, and R. G. Roeder. 1993. Human transcription factor USF stimulates transcription through the initiator elements of the HIV-1 and the Ad-ML promoters. EMBO J. 12:501-511.

7. Edmondson, D. G., and E. N. Olson. 1993. Helix-loop-helix proteins as regulators of muscle-specific transcription. J. Biol. Chem. 268:755-758.

8. Eschenlauer, J. B., M. W. Kaiser, V. L. Gerlach, and D. A. Brow. 1993. Architecture of a yeast U6 RNA gene promoter. Mol. Cell. Biol. 13:3015-3026.

9. Henikoff, S. 1984. Unidirectional digestion with exonuclease III creates targeted breakpoints for DNA sequencing. Gene 28:351359.

10. Kirschbaum, B. J., P. Pognonec, and R. G. Roeder. 1992. Definition of the transcriptional activation domain of recombinant 43-kilodalton USF. Mol. Cell. Biol. 12:5094-5101.

11. Kozlowski, M. T., L. Gan, J. M. Venuti, M. Sawadogo, and W. H. Klein. 1991. Sea urchin USF: a helix-loop-helix protein active in embryonic ectoderm cells. Dev. Biol. 148:625-630.

12. Kunkel, G. R., R. L. Maser, J. P. Calvet, and T. Pederson. 1986. U6 small nuclear RNA is transcribed by RNA polymerase III. Proc. Natl. Acad. Sci. USA 83:8575-8579.

13. Kunkel, G. R., and T. Pederson. 1988. Upstream elements required for efficient transcription of a human U6 RNA gene resemble those of $\mathrm{U} 1$ and $\mathrm{U} 2$ genes even though a different polymerase is used. Genes Dev. 2:196-204.

14. Kunkel, G. R., and T. Pederson. 1989. Transcription of a human U6 small nuclear RNA gene in vivo withstands deletion of intragenic sequences but not of an upstream TATATA box. Nucleic Acids Res. 17:7371-7379.

15. Kunkel, T. A. 1985 . Rapid and efficient site-specific mutagenesis without phenotypic selection. Proc. Natl. Acad. Sci. USA 82:488492.

16. Lenardo, M., J. W. Pierce, and D. Baltimore. 1987. Protein binding in Ig gene enhancers determines transcriptional activity and inducibility. Science 236:1573-1577.

17. Lescure, A., G. Tebb, I. W. Mattaj, A. Krol, and P. Carbon. 1992. A factor with Sp1 DNA-binding specificity stimulates Xenopus U6 snRNA in vivo transcription by RNA polymerase III. J. Mol. Biol. 228:387-394.

18. Li, J.-M., R. A. Parsons, and W. F. Marzluff. Unpublished results.

19. Lobo, S. M., S. Ifill, and N. Hernandez. 1990. Cis-acting elements required for RNA polymerase II and III transcription in the human U2 and U6 snRNA promoters. Nucleic Acids Res. 18: 2891-2899.

20. Lobo, S. M., M. Tanaka, M. L. Sullivan, and N. Hernandez. 1992. A TBP complex essential for transcription from TATA-less but not TATA-containing RNA polymerase III promoters is part of the TFIIIB fraction. Cell 71:1029-1040.

21. Lund, E., and J. E. Dahlberg. 1992. Cyclic $2^{\prime}, 3^{\prime}$-phosphates and nontemplated nucleotides at the $3^{\prime}$ end of spliceosomal U6 small nuclear RNA's. Science 255:327-330.

22. Luo, Y., H. Fujii, T. Gerster, and R. G. Roeder. 1992. A novel B cell-derived coactivator potentiates the activation of immunoglobulin promoters by octamer-binding transcription factors. Cell 71:231-241.

23. Morris, G. F., D. H. Price, and W. F. Marzluff. 1986. Synthesis of U1 RNA in a DNA-dependent system from sea urchin embryos. Proc. Natl. Acad. Sci. USA 83:3674-3678.

24. Murphy, S., C. Di Liegro, and M. Melli. 1987. The in vitro transcription of the 7SK RNA gene by RNA polymerase III is dependent only on the presence of an upstream promoter. Cell 51:81-87.

25. Murphy, S., A. Pierani, C. Scheidereit, M. Melli, and R. G. Roeder. 1989. Purified octamer binding transcription factors stimulate RNA polymerase III-mediated transcription of the 7SK RNA gene. Cell 59:1071-1080.

26. Murphy, S., J.-B. Yoon, T. Gerster, and R. G. Roeder. 1992. Oct-1 and Oct-2 potentiate functional interactions of a transcription factor with the proximal sequence element of small nuclear RNA genes. Mol. Cell. Biol. 12:3247-3261.

27. Parry, H. D., D. Scherly, and I. W. Mattaj. 1989. 'Snurpogenesis': the transcription and assembly of U snRNP components. Trends Biochem. Sci. 14:15-19.

28. Reddy, R., D. Henning, G. Das, M. Harless, and D. Wright. 1987. The capped U6 small nuclear RNA is transcribed by RNA 
polymerase III. J. Biol. Chem. 262:75-81.

29. Sadowski, C. L., R. W. Henry, S. M. Lobo, and N. Hernandez. 1993. Targeting TBP to a non-TATA box cis-regulatory element: a TBP-containing complex activates transcription from snRNA promoters through the PSE. Genes Dev. 7:1535-1548.

29a.Sakallah, S. A., D. R. Norton, W. Zhang, and W. F. Marzluff. Isolation and characterization of the tandemly repeated U6 genes from the sea urchin Strongylocentrotus purpuratus. Biochim. Biophys. Acta, in press.

30. Sawadogo, M., M. W. Van Dyke, P. D. Gregor, and R. G. Roeder. 1988. Multiple forms of the human gene-specific transcription factor USF. I. Complete purification and identification of USF from HeLa cell nuclei. J. Biol. Chem. 263:11985-11993.

31. Simmen, K. A., R. Waldschmidt, J. Bernués, H. D. Parry, K. H. Seifart, and I. W. Mattaj. 1992. Proximal sequence element factor binding and species specificity in vertebrate U6 snRNA promoters. J. Mol. Biol. 223:873-884.

32. Southgate, C., and M. Busslinger. 1989. In vivo and in vitro expression of U7 snRNA genes: cis- and trans-acting elements required for RNA polymerase II-directed transcription. EMBO J. 8:539-549.

33. Stefanovic, B., and W. F. Marzluff. 1992. Characterization of two developmentally regulated sea urchin U2 small nuclear RNA promoters: a common required TATA sequence and independent proximal and distal elements. Mol. Cell. Biol. 12:650-660.

34. Tanaka, M., J.-S. Lai, and W. Herr. 1992. Promoter-selective activation domains in Oct-1 and Oct-2 direct differential activation of an snRNA and mRNA promoter. Cell 68:755-767.

35. Thomas, J., K. Lea, E. Zucker-Aprison, and T. Blumenthal. 1990. The spliceosomal snRNAs of Caenorhabditis elegans. Nucleic Acids Res. 18:2633-2642.

36. Tomlinson, C. R., M. T. Kozlowski, and W. H. Klein. 1990 Ectoderm nuclei from sea urchin embryos contain a Spec-DNA binding protein similar to the vertebrate transcription factor USF. Development 110:259-272.

37. Waibel, F., and W. Filipowicz. 1990. U6 snRNA genes of Arabidopsis are transcribed by RNA polymerase III but contain the same two upstream promoter elements as RNA polymerase II-transcribed U-snRNA genes. Nucleic Acids Res. 18:3451-3458.

38. Waibel, F., and W. Filipowicz. 1990. RNA-polymerase specificity of transcription of Arabidopsis U snRNA genes determined by promoter element spacing. Nature (London) 346:199-202.

39. Waldschmidt, R., I. Wanandi, and K. H. Seifart. 1991. Identification of transcription factors required for the expression of mammalian U6 genes in vitro. EMBO J. 10:2595-2603.

40. Wendelburg, B. W., and W. F. Marzluff. 1992. Two promoter elements are necessary and sufficient for expression of the sea urchin U1 snRNA gene. Nucleic Acids Res. 20:3743-3751. 